\title{
miR-129-5p suppresses breast cancer proliferation by targeting CBX4
}

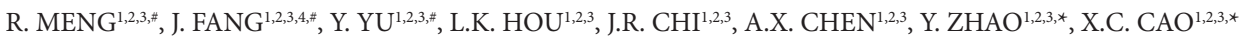 \\ ${ }^{1}$ The First Department of Breast Cancer, Tianjin Medical University Cancer Institute and Hospital, National Clinical Research Center for Cancer, \\ Tianjin 300060, China; ${ }^{2}$ Key Laboratory of Cancer Prevention and Therapy, Tianjin 300060, China; ${ }^{3}$ Key Laboratory of Breast Cancer Preven- \\ tion and Therapy, Tianjin Medical University, Ministry of Education, Tianjin 300060, China; ${ }^{4}$ Department of Head-neck and Breast Surgery, \\ Anhui Provincial Hospital Affiliated to Anhui Medical University, Anhui Provincial Cancer Hospital, Hefei 230031, China
}

*Correspondence: caoxuchen@tmu.edu.cn; zhaoyingtjmu@126.com

${ }^{*}$ Contributed equally to this work.

Received August 14, 2017 / Accepted January 5, 2018

\begin{abstract}
Deregulation of microRNA (miRNA) is closely related to cancer development and progression. Our previous study identified that miR-129-5p suppresses proliferation and metastasis in breast cancer cells. Herein, we determined that CBX4 is a miR-129-5p target gene. CBX4 is up-regulated in breast cancer tissues and while its over-expression promotes cell proliferation, its knockdown suppresses cell proliferation in breast cancer cells. Furthermore, CBX4 mediates miR-129-5p-induced inhibition of cell proliferation and negatively correlates with the expression of miR-129-5p expression. These combined results suggest that CBX4 is an oncogene in breast cancer cells, and that it may provide a novel therapeutic strategy for breast cancer treatment.
\end{abstract}

Key words: CBX4, miR-129-5p, proliferation, breast cancer

Breast cancer has one of the highest malignancies in female tumors [1] and is the most common malignant tumor and the third cause of cancer mortality in China. Although its incidence is increasing, the trend in the number of related deaths is decreasing [2]. While this is due to earlier detection and treatment, it still remains a matter for high public health concern. Therefore, identifying new genes and pathways involved in breast cancer will help develop faster and safer diagnosis and improve its prognosis and treatment.

MicroRNAs (miRNAs) are a group of non-coding, single-stranded RNAs which normally contain 18-22 nucleotides. They have been clearly demonstrated to play a crucial role in cell proliferation, apoptosis, differentiation, signaling pathways and carcinogenesis by binding to the 3' untranslated region (UTR) of their target mRNAs [3]. miR-129-5p is located in a fragile site in chromosome $7 \mathrm{q} 32$ and its abnormal expression is observed in many malignant tumors including, glioma, and bladder, non-small cell lung, gastric and colorectal cancers, and in medullary thyroid and hepatocellular carcinomas [4-10]. Moreover, over-expression of miR-129-5p inhibits breast cancer motility and decreases radio-resistance $[8,11,12]$, and its down-regulation participates in cancer metastasis through a Twist1-Snail feedback-loop-mediated EMT.
Chromobox 4 (CBX4), also known as polycomb 2 (Pc2), is a special chromobox protein because it is not only a transcriptional repressor but also a SUMO E3 ligase [13], and it has also recently been identified as an oncogene and therapeutic target in hepatocellular carcinoma [3, 14-16]. CBX4 increases HIF-1a transcriptional activity by promoting HIF-1a SUMOylation and this depends on the CBX4 SUMO-interacting motifs [14]. While CBX4 may also act as a tumor suppressor by recruiting HDAC3 to the Runx2 promoter in colorectal carcinoma [13], its role in breast cancer remains unclear.

In addition, although miR-129-5p has been identified as a tumor suppressor in breast cancer, the target gene still requires clarification. Herein, we investigated miR-129-5p regulation mechanisms in breast cancer cells and found that CBX4 is an miR-129-5p target.

\section{Materials and methods}

Cell culture. MCF10A, MCF7, T47D, MDA-MB-468, MDA-MB-231, SKBR3 and 293FT cell lines were obtained from the Cell Bank of the Chinese Academy of Sciences (Shanghai, China) and cultured as previously described [8]. All cell lines were cultured at $37^{\circ} \mathrm{C}$ with $10 \% \mathrm{FBS}$, $100 \mu \mathrm{g} / \mathrm{mL}$ streptomycin and 100 units $/ \mathrm{mL}$ penicillin 
(Thermo Fisher, Waltham, MA, USA). The cells were expanded immediately and multiple aliquots were cryopreserved. Cells were used within 6 months of resuscitation.

Clinical samples. Breast cancer specimens were obtained from Tianjin Medical University Cancer Institute and Hospital. A total of 30 primary breast cancer tissues and the paired adjacent normal breast tissue specimens were studied. All tumors were from patients with newly diagnosed breast cancer who had received no therapy before sample collection. This study was approved by the Institutional Review Board of the Tianjin Medical University Cancer Institute and Hospital and written consent was obtained from all participants. The clinical characteristics of breast patients are summarized in Table 1 .

Plasmids, miRNAs, and small interfering RNAs. The ORF of human CBX4 gene was amplified by PCR in the 293FT cell line and amplified fragments were subcloned into the pcDNA3.1 vector. The CBX4 3'-UTR containing miR-129-5p binding site or miR-129-5p binding site mutated fragments were cloned into pGL3-Control vector (Promega, Madison, WI, USA; CBX4-wt and CBX4-mu). The miR-129-5p mimic and inhibitor, CBX4 gene-specific short interfering (siRNA), and non-specific control siRNA were all purchased from RiboBio (Shanghai, China).

Transfection. miR-129-5p mimic, miR-129-5p inhibitor and the appropriate scrambled controls and siRNAs were transfected into different cell lines using FuGENE HD Transfection Reagent (Promega, Madison, WI, USA) and mammalian expression plasmids were transfected into different cells using TransFast Transfection Reagent (Promega according to the manufacturer's recommendations.

Proliferation assay. MTT and plate colony formation assays evaluated cell proliferation ability, as previously described [17]. $5 \times 10^{3}$ cells were seeded in 96-well plates per well 24 hours after transfection, for MTT assay After required incubation, the cells were then incubated with $10 \mu \mathrm{l} \mathrm{MTT}\left(0.5 \mathrm{mg} / \mathrm{ml}\right.$; Sigma-Aldrich) at $37^{\circ} \mathrm{C}$ for 4 hours, the medium was then removed and precipitated formosan was dissolved in $150 \mu \mathrm{l}$ DMSO. The absorbance at $570 \mathrm{~nm}$ was detected by micro-plate auto-reader (Bio-Rad, Richmond, CA, USA).

Plate colony formation assay was performed 24 hours after transfection, with $5 \times 10^{3}$ cells seeded in a $6 \mathrm{~cm}$ dish. The colonies obtained after 3 weeks were washed with PBS and fixed with $10 \%$ formalin for 15 minutes at room temperature and then washed with PBS followed by staining with hematoxylin. The colonies were counted and compared with control cells.

Luciferase assay. Luciferase assay was performed on extracts from different breast cancer cells co-transfected for 48 hours with the corresponding plasmids, miRNAs, or siRNAs by dual luciferase assay kit (Promega). The results were then normalized against Renilla luciferase activity. All transfections were performed in triplicate.
Western blot. Cells were lysed in protein lysis buffer (20 mM Tris- $\mathrm{HCl} \mathrm{pH} 7.4,5 \mathrm{mM}$ EDTA, $1 \%$ Trition $\mathrm{X}-100,150 \mathrm{mM} \mathrm{NaCl}, 1 \%$ DTT) containing a protease inhibitor cocktail tablet (Roche Molecular Biochemicals, Indianapolis, IN, USA). Protein lysates were resolved by SDS-PAGE, transferred to PVDF membranes (Millipore, Bedford, MA, USA), detected with primary antibody overnight at $4{ }^{\circ} \mathrm{C}$ and incubated with HRP-conjugated secondary antibodies. The blots were then visualized with ECL reagent (Millipore).

RNA extraction and reverse transcription quantitative PCR. The total RNA in cultured cells and surgically resected fresh breast tissues and formalin-fixed paraffinembedded clinical specimens were extracted using mirVana PARIS kit (Thermo Fisher) according to the manufacturer's recommendations. qPCR was performed by GoTaq qPCR Master Mix (Promega) or TaqMan microRNA Reverse Transcription kit (Thermo Fisher) as previously described [8].

Cell cycle distribution analysis. The cells were fixed with $70 \%$ ethanol at $-20^{\circ} \mathrm{C}$ overnight and washed with PBS for cell cycle distribution assay. They were then re-suspended in $0.1 \%$ Triton-X100/PBS and concomitantly treated with Rnase A and stained with $50 \mu \mathrm{g} / \mathrm{ml}$ PI for 15 minutes. The cell cycle distribution was analyzed by BD FACSCanto II (BD Biosciences, San Diego, CA, USA).

Table 1. Breast cancer patient characteristics.

\begin{tabular}{|c|c|c|}
\hline \multirow{2}{*}{ Clinicopathological Factors } & \multicolumn{2}{|c|}{ Patients } \\
\hline & No. & $\%$ \\
\hline \multicolumn{3}{|l|}{ Age (year) } \\
\hline$<55$ & 18 & 60.0 \\
\hline$>=55$ & 12 & 40.0 \\
\hline \multicolumn{3}{|l|}{ Menopausal status } \\
\hline Pre- & 15 & 50.0 \\
\hline Post- & 15 & 50.0 \\
\hline \multicolumn{3}{|l|}{ Pathological stage } \\
\hline $\mathrm{I}+\mathrm{II}$ & 26 & 86.7 \\
\hline III+IV & 4 & 13.3 \\
\hline \multicolumn{3}{|l|}{ Histological grade } \\
\hline $\mathrm{I}+\mathrm{II}$ & 26 & 86.7 \\
\hline III & 4 & 13.3 \\
\hline \multicolumn{3}{|l|}{ Lymph node status } \\
\hline Negative & 12 & 40.0 \\
\hline Positive & 18 & 60.0 \\
\hline \multicolumn{3}{|l|}{ ER status } \\
\hline Positive & 16 & 53.3 \\
\hline Negative & 14 & 46.7 \\
\hline \multicolumn{3}{|l|}{ PR status } \\
\hline Positive & 11 & 36.7 \\
\hline Negative & 19 & 63.3 \\
\hline \multicolumn{3}{|l|}{ HER-2 status } \\
\hline Negative & 21 & 70.0 \\
\hline Positive & 9 & 30.0 \\
\hline
\end{tabular}


Validation of CBX4 mRNA expression in breast cancer tissues. We used the ONCOMINE public cancer microarray database, ONCOMINE, to validate our CBX4 mRNA expression data from breast cancer tissues (http:// www.oncomine.org). We also collected information on CBX4 mRNA expression from the TCGA database (A_23_P89623); including normal breast tissues $(\mathrm{n}=61)$ and invasive ductal breast carcinoma $(\mathrm{n}=389)$.

Statistical analysis. Data is presented as mean \pm standard deviation. The Student's t-test (2-tailed) was used to determine the differences between experimental and control groups and significance was set at $\mathrm{p}<0.05$. All calculations were performed by SPSS for Windows statistical software package (SPSS Inc., Chicago, IL, USA).

\section{Results}

CBX4 is a target of miR-129-5p. Our previous study indicated that miR-129-5p inhibits breast cancer progression and is associated with favorable outcome in patients with breast cancer [8]. Herein, we focused on breast cancer

A

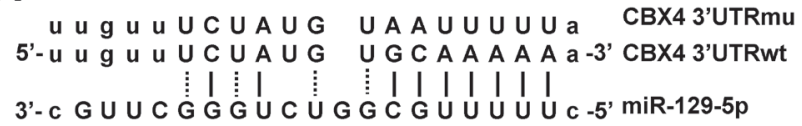
B
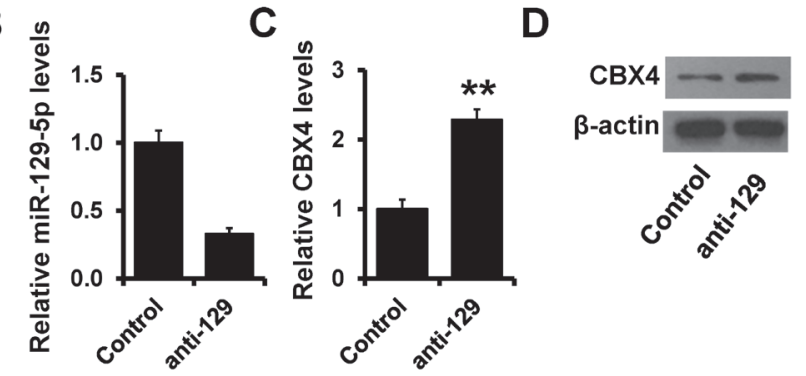

E

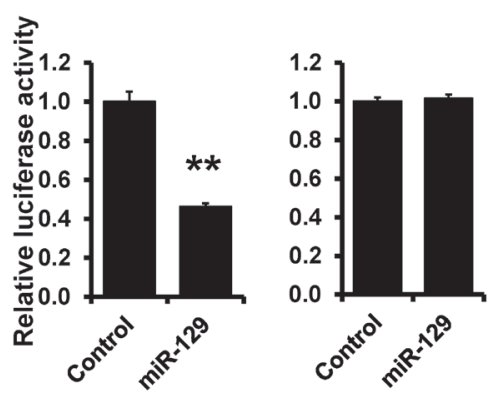

Figure 1. CBX4 is a target of miR-129-5p. (A) Predicted miR-129-5p binding with CBX4 3'UTR; (B and C) mRNA expression of miR-129-5p (B) and CBX4; (C) in miR-129-5p inhibitor-transfected MCF10A cells by RT-qPCR.(D) The protein expression of CBX4 in miR-129-5p-depleted MCF10A cells.(E) Dual luciferase reporter system analysis validated the CBX miR-129-5p target. A3'UTR fragment containing the predicted miR-129-5p targeting site of CBX4 was fused downstream of the Luc gene (left). A miR-129-5p mutated binding site was also constructed (right). ${ }^{* *} \mathbf{p}<0.01$.
miR-129-5p target genes. The miRanda and TargetScan target prediction programs identified CBX4 as a putative miR-129-5p target (Figure 1A). We depleted miR-129-5p expression in MCF10A cells (Figure 1B) and RT-PCR and western blot determined increased CBX4 expression (Figures 1C, D). To further confirm this regulation, CBX4 3'-UTR and its mutant containing the putative miR-129-5p binding sites were cloned into the downstream of the luciferase ORF. These reporter constructs were co-transfected into 293FT cells with miR-129-5p mimic. Over-expression of miR-129-5p significantly decreased the luciferase activity compared to that of control cells (Figure 1E left). This effect was abolished with mutated CBX4 3'-UTR; where the miR-129-5p binding sites were inactivated by site-directed mutagenesis (Figure 1E right).

CBX4 promotes breast cancer proliferation. Western blot determined CBX4 expression in the T47D, MCF7, MDA-MB-231, MDA-MB-468 and SKBR3 breast cancer cell lines and in the normal MCF10A breast cell line. Results confirmed that $\mathrm{CBX} 4$ is up-regulated in breast cancer cell lines compared to MCF10A cells (Figure 2A). We next evaluated the role of CBX4 in breast cancer proliferation by transfecting pcDNA3.1-CBX4 into MCF10A cells (Figure 2B). The MTT and colony formation assays indicated that over-expression of $\mathrm{CBX} 4$ enhanced MCF10A cell proliferation (Figures 2C, D). In contrast, depletion of CBX4 inhibited cell proliferation in SKBR3 cells (Figures 2E, G). Cell cycle analysis indicated that $\mathrm{CBX} 4$ depletion led to $\mathrm{G} 2 / \mathrm{M}$ arrest (Figure $2 \mathrm{H}$ ). Furthermore, CDC2 activity was higher, with lower CDC2-Y15 expression in CBX4-overexpressed MCF10A cells; and lower, with higher CDK1-Y15 expression in the CBX4-depleted SKBR3 cells (Figure 2I). These results therefore indicate that $\mathrm{CBX} 4$ promotes breast cancer proliferation.

Depletion of miR-129-5p promotes breast cancer proliferation through up-regulating CBX4 expression.

We investigate if miR-129-5p regulates breast cancer proliferation by regulating CBX4 expression. We transfected miR-129-5p inhibitor with and without CBX4 siRNA into the MCF10A cells (Figures 3A, B). Here, MTT and colony formation showed that miR-129-5p depletion promotes cell proliferation (Figures 3C, D) and CBX4 knockdown reverses this effect in miR-129-5p-depleted MCF10A cells (Figures 3C, D). Cell cycle distribution then indicated that depletion of $\mathrm{CBX} 4$ led to $\mathrm{G} 2 / \mathrm{M}$ arrest in miR-129-5p-depleted MCF10A cells (Figure 3E) and CDC2 activity was also reversed in both CBX4 and miR-129$5 p$-depleted MCF10A cells (Figure 3B). These combined results confirmed that mR-129-5p promotes breast cancer proliferation by up-regulating CBX4 expression.

CBX4 is up-regulated in breast cancer. RT-qPCR determined the expression of CBX4 in 30 breast cancer tissues and the paired normal breast tissues, and this revealed that the $\mathrm{CBX} 4$ expression was up-regulated 
A

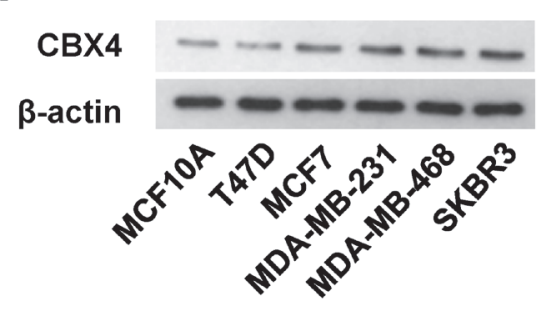

B

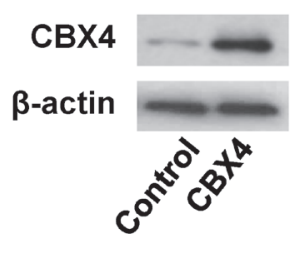

C

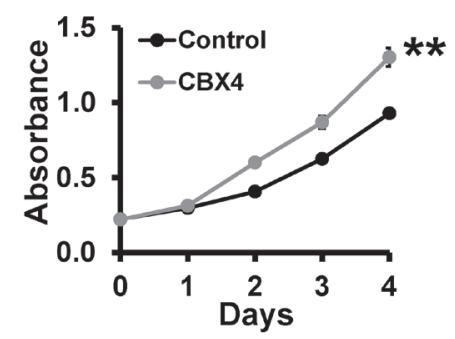

F

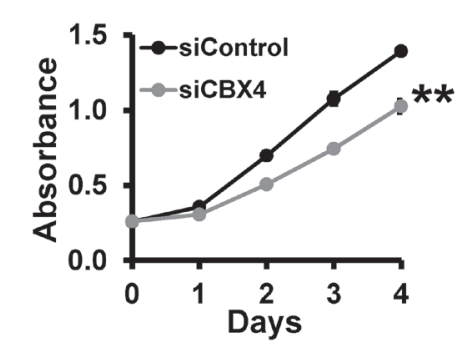

D
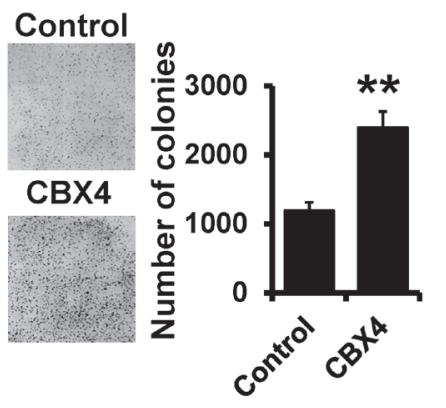

E

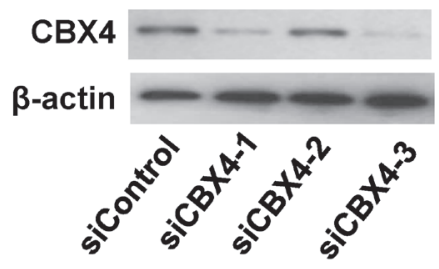

H
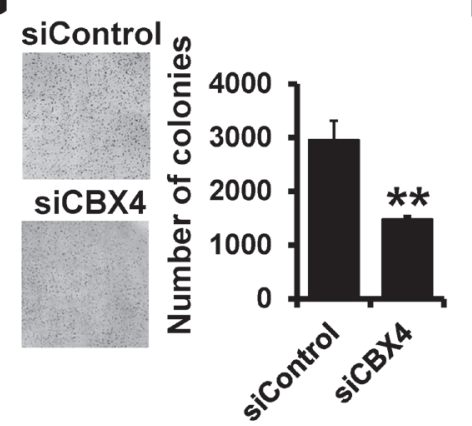

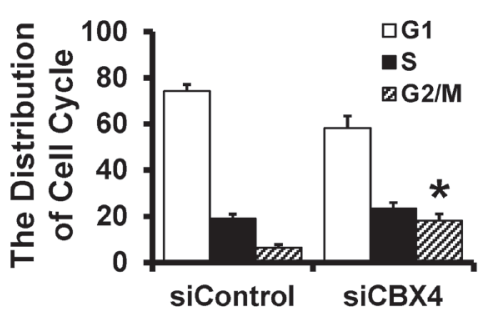

I

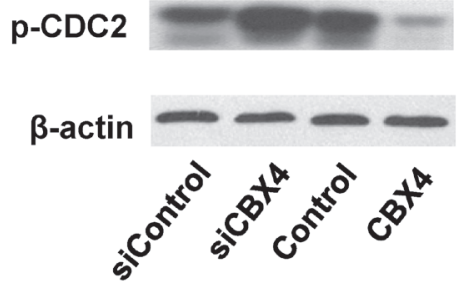

Figure 2. CBX4 promotes breast cancer proliferation. A) The expression of CBX4 in breast cancer cell lines and normal breast cell line by western blot. B) The expression of CBX4 in pcDNA3.1-CBX4-transfected MCF10A cells. C) MTT analysis of cells as in (B). D) Colony formation analysis of cells as in (B). E) The expression of CBX4 in CBX4 siRNAs-transfected SKBR3 cells by western blot. F) MTT analysis of CBX4-depleted SKBR3 cells. G) Colony formation analysis of CBX4-depleted SKBR3 cells. H) The cell cycle distribution of CBX4-depleted SKBR3 cells by FACS. I) Expression of p-CDC2 in indicated cells by western blot. ${ }^{\star *} \mathrm{p}<0.01,{ }^{\star} \mathrm{p}<0.05$.

(>1.5-fold) in 22 of the 30 tissues (Figure $4 \mathrm{~A})$. This was further confirmed by TCGA (Figure 4B), where miR-129-5p expression also negatively correlated with CBX4 expression (Figure 4C). Thus, results indicated that CBX4 is up-regulated in breast cancer and negatively correlates with miR-129-5p expression.

\section{Discussion}

Herein, we demonstrated that CBX4 is up-regulated in breast cancer and promotes breast cancer proliferation. Furthermore, CBX4 is a target of miR-129-5p and mediates miR-129-5p-induced inhibition of breast cancer proliferation. Clinically, the expression of miR-129-5p negatively correlates with CBX4 expression.
Our previous study indicated that miR-129-5p is downregulated in breast cancer and the down-regulation of miR-129-5p is associated with poor outcome. In contrast, although miR-129-5p over-expression suppresses breast cancer proliferation and metastasis through regulation of Twist and Snail [8], the miR-129-5p target still requires clarification.

Polycomb group proteins (PcGs) are reportedly linked to the development and progression of various cancers [18], and their deregulation always leads to activation of developmental pathways, thus enhancing cell proliferation [19]. CBX4 is a unique PcG protein which regulates multiple key proteins in cell biological function by its small ubiquitin-related modifier (SUMO) E3 ligase activity; including Bim-1 and centrin-2 [20,21].While CBX4 study 
Figure 3. Depletion of miR-129-5p promotes breast cancer proliferation in a CBX4-dependent manner. A) The expression of miR-129-5p in miR-129-5p-transfected MCF10A cells with and without $\mathrm{CBX} 4$ siRNA. B) The expression of $\mathrm{CBX} 4$ and $\mathrm{p}$ CDC2 in cells as in (A). C) MTT analysis of cells as in (A). D) Colony formation analysis of cells as in (A). E) The cell cycle distribution of cells as in $(\mathrm{A}) .{ }^{* *} \mathrm{p}<0.01,{ }^{*} \mathrm{p}<0.05$.

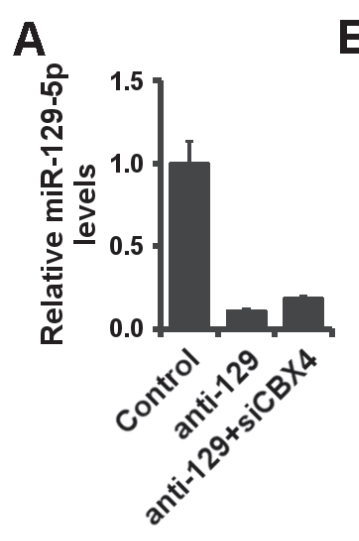

B

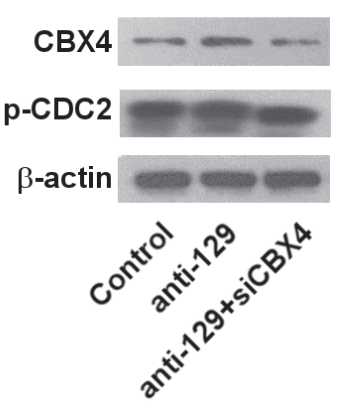

C

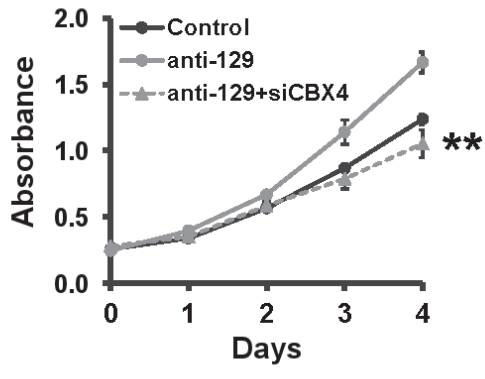

D

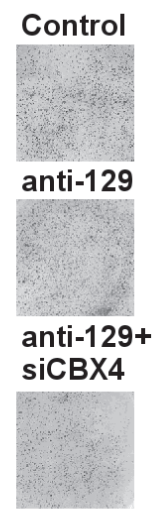

E

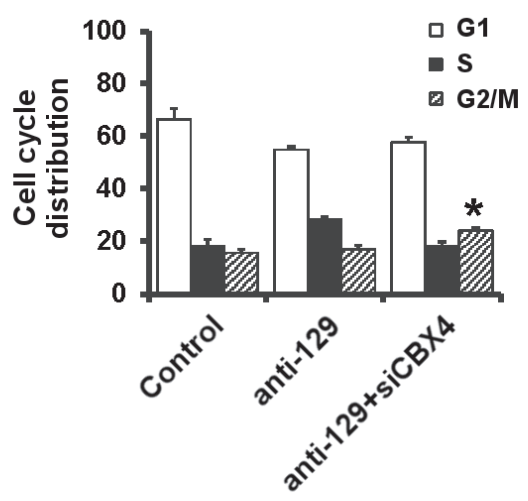

A

B

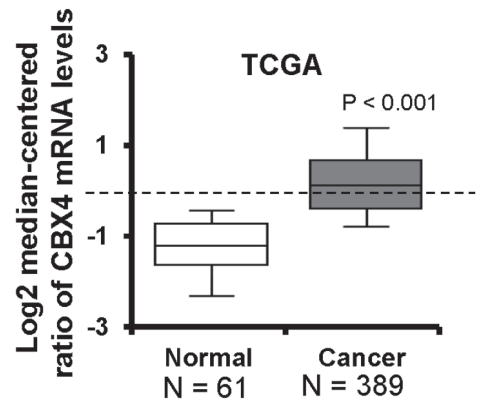

Figure 4. CBX4 is up-regulated in breast cancer and negatively correlates with miR-129-5p expression. A) The expression of miR-129-5p in 30 breast cancer tissues and the paired normal breast tissues by RTqPCR. B) The expression of CBX4 in TCGA database. C) Correlated expression of miR-129-5p and CBX4.

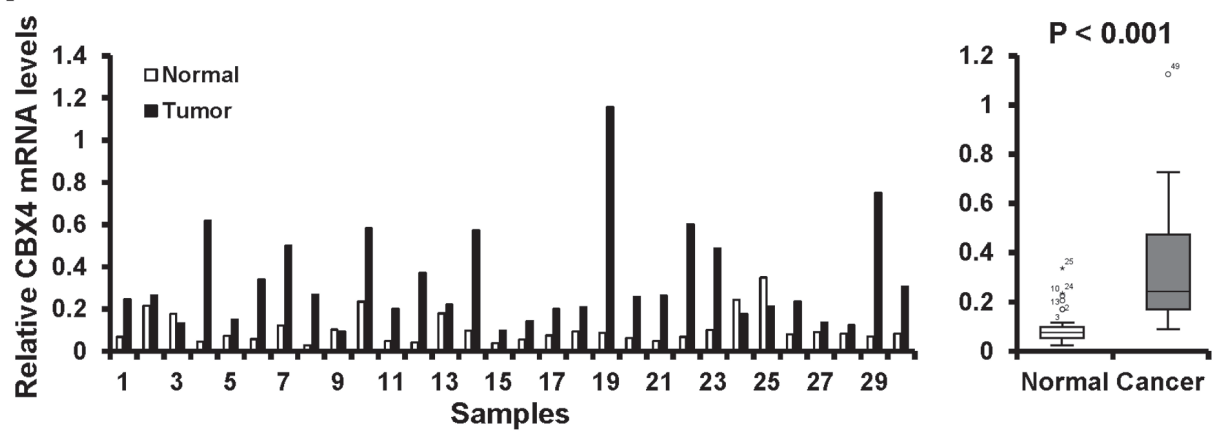

C

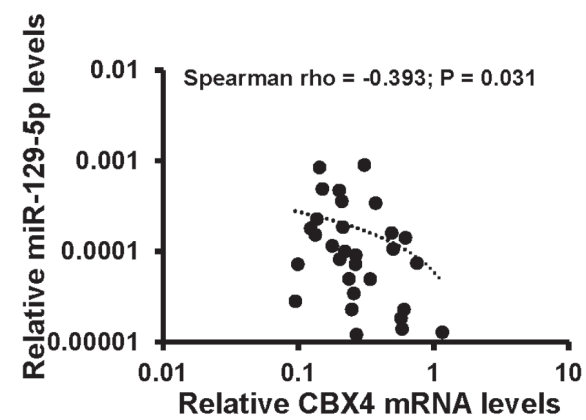

Relative CBX4 mRNA levels

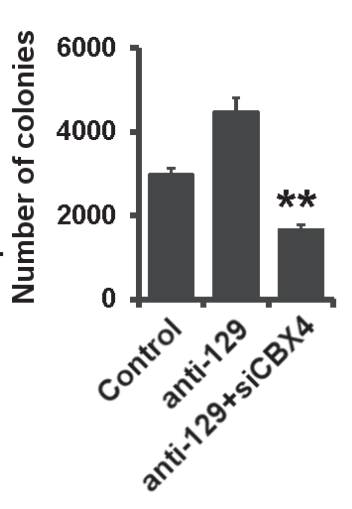


in carcinogenesis and progression is extremely lacking, and this applies especially to breast cancer, recent studies have confirmed that CBX4 acts an oncogene in hepatocellular cancer development and progression [14-16, 22]. This strongly supports our finding that CBX4 depletion results in significant inhibition of cell growth, while its over-expression increases breast cancer cell proliferation. Yang et al. [23] also indicated that CBX4 positively correlates with human osteosarcoma tumor growth, survival and activation of HIF-1 $\alpha$ signaling. Furthermore, our results confirm that CBX4 mediates miR-129-5p-induced inhibition of cell growth in breast cancer cells.

In conclusion, herein we demonstrated that CBX4 is up-regulated in human breast cancer tissues and cell lines, and most importantly that CBX4 is an miR-129-5p target which promotes breast cancer cell proliferation. This provides compelling evidence that CBX4 could be a successful target for breast cancer therapy.

Acknowledgments: This study was supported by the National Natural Science Foundation of China (No. 81372843, No. 81472472, No. 81502518 and No. 81502300), and the Major Program of Applied Basic Research Projects of Tianjin (No. 17JCQNJC10400).

\section{References}

[1] SMITH RA, MANASSARAM-BAPTISTE D, BROOKS D, DOROSHENK M, FEDEWA $S$ et al. Cancer screening in the United States, 2015: a review of current American cancer society guidelines and current issues in cancer screening. CA Cancer J Clin 2015; 65: 30-54. https://doi.org/10.3322/ caac. 21261

[2] WONG IO, SCHOOLING CM, COWLING BJ, LEUNG GM. Breast cancer incidence and mortality in a transitioning Chinese population: current and future trends. Br J Cancer 2015; 112: 167-170. https://doi.org/10.1038/bjc.2014.532

[3] LIU HT, GAO P. The roles of microRNAs related with progression and metastasis in human cancers. Tumour Biol 2016. https://doi.org/10.1007/s13277-016-5436-9

[4] SHEN N, HUANG X, LI J. Upregulation of miR-129-5p affects laryngeal cancer cell proliferation, invasiveness, and migration by affecting STAT3 expression. Tumour Biol 2016; 37: 1789-1796. https://doi.org/10.1007/s13277-015-3969-y

[5] DUAN L, HAO X, LIU Z, ZHANG Y, ZHANG G. MiR-129$5 \mathrm{p}$ is down-regulated and involved in the growth, apoptosis and migration of medullary thyroid carcinoma cells through targeting RET, FEBS Lett 2014; 588: 1644-1651. https://doi. org/10.1016/j.febslet.2014.03.002

[6] DOSSING KB, BINDERUP T, KACZKOWSKI B, JACOBSEN A, ROSSING M et al. Down-Regulation of miR-129-5p and the let-7 Family in Neuroendocrine Tumors and Metastases Leads to Up-Regulation of Their Targets Egr1, G3bp1, Hmga2 and Bach1. Genes (Basel) 2014; 6: 1-21. https://doi. org/10.3390/genes6010001
[7] WU Q, YANG Z, XIA L, NIE Y, WU K et al. Methylation of miR-129-5p CpG island modulates multi-drug resistance in gastric cancer by targeting $\mathrm{ABC}$ transporters. Oncotarget 2014; 5: 11552-11563. https://doi.org/10.18632/oncotarget.2594

[8] YU Y, ZHAO Y, SUN XH, GE J, ZHANG B et al. Downregulation of miR-129-5p via the Twist1-Snail feedback loop stimulates the epithelial-mesenchymal transition and is associated with poor prognosis in breast cancer. Oncotarget 2015; 6: 34423-34436. https://doi.org/10.18632/oncotarget.5406

[9] MA N, CHEN F, SHEN SL, CHEN W, CHEN LZ et al. MicroRNA-129-5p inhibits hepatocellular carcinoma cell metastasis and invasion via targeting ETS1. Biochem Biophys Res Commun 2015; 461: 618-623. https://doi.org/10.1016/j. bbrc.2015.04.075

[10] LONG XH, ZHOU YF, PENG AF, ZHANG ZH, CHEN XY et al. Demethylation-mediated miR-129-5p up-regulation inhibits malignant phenotype of osteogenic osteosarcoma by targeting Homo sapiens valosin-containing protein (VCP). Tumour Biol 2015; 36: 3799-3806. https://doi.org/10.1007/ s13277-014-3021-7

[11] LUO J, CHEN J, HE L. mir-129-5p Attenuates IrradiationInduced Autophagy and Decreases Radioresistance of Breast Cancer Cells by Targeting HMGB1. Med Sci Monit 2015; 21 : 4122-4129.

[12] TANG X, TANG J, LIU X, ZENG L, CHENG C et al. Downregulation of miR-129-2 by promoter hypermethylation regulates breast cancer cell proliferation and apoptosis. Oncol Rep 2016; 35: 2963-2969. https://doi.org/10.3892/ or.2016.4647

[13] WANG X1, LI L1, WU Y1, ZHANG R1, ZHANG M et al. CBX4 Suppresses Metastasis via Recruitment of HDAC3 to the Runx2 Promoter in Colorectal Carcinoma. Cancer Res 2016; 76: 7277-7289. https://doi.org/10.1158/0008-5472. CAN-16-2100

[14] LI J, XU Y, LONG XD, WANG W, JIAO HK et al. Cbx4 governs HIF-1alpha to potentiate angiogenesis of hepatocellular carcinoma by its SUMO E3 ligase activity. Cancer Cell 2014; 25: 118-131. https://doi.org/10.1016/j.ccr.2013.12.008

[15] WANG B, TANG J, LIAO D, WANG G, ZHANG $\mathrm{M}$ et al. Chromobox homolog 4 is correlated with prognosis and tumor cell growth in hepatocellular carcinoma. Ann Surg Oncol 2013; 20: S684-692. https://doi.org/10.1245/s10434-0133171-7

[16] JIAO HK, XU Y, LI J, WANG W, MEI Z et al. Prognostic significance of $\mathrm{Cbx} 4$ expression and its beneficial effect for transarterial chemoembolization in hepatocellular carcinoma. Cell Death Dis 2015; 6: e1689. https://doi.org/10.1038/ cddis. 2015.57

[17] CAO XC, YU Y, HOU LK, SUN XH, GE J et al. miR-142-3p inhibits cancer cell proliferation by targeting CDC25C. Cell Prolif 2016; 49: 58-68. https://doi.org/10.1111/cpr.12235

[18] WANG W, QIN JJ, VORUGANTI S, NAG S, ZHOU J et al. Polycomb Group (PcG) Proteins and Human Cancers: Multifaceted Functions and Therapeutic Implications. Med Res Rev 2015; 35: 1220-1267. https://doi.org/10.1002/med.21358 
[19] MILLS AA. Throwing the cancer switch: reciprocal roles of polycomb and trithorax proteins. Nat Rev Cancer 2010; 10: 669-682. https://doi.org/10.1038/nrc2931

[20] ISMAIL IH, GAGNE JP, CARON MC, MCDONALD D, XU $\mathrm{Z}$ et al. CBX4-mediated SUMO modification regulates BMI1 recruitment at sites of DNA damage. Nucleic Acids Res 2012; 40: 5497-5510. https://doi.org/10.1093/nar/gks222

[21] KLEIN UR, NIGG EA. SUMO-dependent regulation of centrin-2. J Cell Sci 2009; 122: 3312-3321. https://doi. org/10.1242/jcs.050245
[22] ZHENG C, LI J, WANG Q, LIU W, ZHOU J et al. MicroRNA-195 functions as a tumor suppressor by inhibiting CBX4 in hepatocellular carcinoma. Oncol Rep 2015; 33: 11151122. https://doi.org/10.3892/or.2015.3734

[23] YANG J, CHENG D, ZHU B, ZHOU S, YING T et al. Chromobox Homolog 4 is Positively Correlated to Tumor Growth, Survival and Activation of HIF-1alpha Signaling in Human Osteosarcoma under Normoxic Condition. J Cancer 2016; 7: 427-435. https://doi.org/10.7150/jca.13749 